\title{
Açúcar granulado ou em gel no tratamento de feridas em cães
}

\author{
Granulated sugar and sugar gel in treating canine wounds
}

\author{
Gabriele Maria Callegaro Serafini ${ }^{\mathrm{I}}$ João Eduardo Wallau Schossler ${ }^{\mathrm{II}}$ Anne Santos do Amaral ${ }^{\mathrm{II}}$ \\ Luciana Hermes Dutra ${ }^{\text {III }}$ Angela Piantá Dibi ${ }^{\text {III }}$ Priscila Drogemoller ${ }^{\text {III }}$ Cristiane de Lima Athayde ${ }^{\text {III }}$
}

\section{RESUMO}

O açúcar é um dos produtos mais utilizados para tratamento de feridas em medicina veterinária. Sua principal vantagem é o efeito higroscópico nos tecidos e morte das bactérias por plasmólise, tornando-o um bactericida pelo efeito físico realizado, sem levar à resistência bacteriana. O objetivo deste experimento foi comparar a evolução cicatricial de feridas cutâneas com o uso tópico de açúcar na forma granulada e na forma de gel. Foram tratadas 16 feridas de cães, das quais oito receberam tratamento com açúcar granulado (grupo A) e oito com gel de açúcar (grupo G). O tempo de tratamento, independente do grupo, levou, no mínimo, sete dias e, no máximo, 14. Quanto à aplicabilidade, o gel demonstrou melhor adesão nas feridas $e$ preenchimento do produto no subcutâneo de forma mais efetiva que o açúcar granulado. Conclui-se que tanto o gel quanto o açúcar foram efetivos na cicatrização das feridas dos animais deste experimento, sendo que o gel demonstrou precocidade na retração cicatricial nos primeiros sete dias.

Palavras-chave: cura de feridas cutâneas, açúcar, resistência bacteriana.

\section{ABSTRACT}

Sugar is one of the most widely used products in the treatment of wounds in veterinary medicine. Its main advantage is the hygroscopic effect on tissues and the bacterial death by plasmolysis, making it a bactericidal agent due to the physical effect observed, without leading to bacterial resistance. The aim of this experiment was to compare cicatricial evolution of cutaneous wounds with the topical use of sugar either granulated or as gel. Sixteen canine wounds were treated: eight with granulated sugar (group A) and eight with sugar gel (group G). Treatment time, independent of the group, took at least seven days and a maximum of 14 . Concerning applicability, gel sugar showed better adhesion to wounds and subcutaneous filling more effectively that granulated sugar. It is concluded that both granulated and gel sugar were effective in healing skin wounds, the gel being precocious in cicatricial retraction within the first seven days of treatment.

Key words: skin wounds healing, sugar forms, bacterial resistance.

\section{INTRODUÇÃO}

Ferida é toda e qualquer solução de continuidade da pele, geralmente produzida por ação traumática externa (MELO et al., 2009). Com relação à classificação, as feridas podem ser abertas ou fechadas, sendo que ferimentos fechados relacionam-se às contusões, pois não há ruptura da pele, já nas feridas abertas, ocorre laceração ou perda cutânea e são classificadas em abrasão, avulsão, incisas, laceradas e por punção. As feridas abertas também são classificadas com base no tempo de exposição e contaminação bacteriana. Considera-se de classe 1 as feridas com até seis horas de duração, com contaminação mínima. Classe 2, feridas de seis a 12 horas com contaminação significativa e classe 3 , feridas de 12 horas ou mais de evolução, macroscopicamente contaminadas (WALDRO \& ZIMMERMAN-POPE, 2007).

'Programa de Pós-graduação em Medicina Veterinária, Universidade Federal de Santa Maria (UFSM), 97105-900, Santa Maria, RS, Brasil. E-mail: gabrieleserafini@yahoo.com.br. Autor para correspondência.

"Departamento de Clínica de Pequenos Animais, UFSM, Santa Maria, RS, Brasil.

${ }^{\mathrm{II}}$ Curso de Medicina Veterinária, UFSM, Santa Maria, RS, Brasil. 
O tratamento de feridas infectadas é um tema de relevante importância na prática clínico-cirúrgica, especialmente no momento atual de aparecimento crescente de microrganismos resistentes, decorrente do uso indiscriminado de antimicrobianos (ALVES et al., 2008). Nesse contexto, diversas terapias alternativas têm sido empregadas, sendo o açúcar um dos agentes tópicos cicatrizantes e antimicrobianos mais amplamente utilizados (PIEPER \& CALIRI, 2003).

CHIRIFE et al. (1983) propuseram que uma importante função do açúcar em feridas infectadas é criar um ambiente com baixa atividade de água. Uma vez que bactérias, como todas as outras formas de vida, requerem água para sobreviver, a adição de um soluto como o açúcar promove concentração na solução aquosa da ferida, ficando a atividade de água do local abaixo do limite necessário para que a bactéria se desenvolva (CHRISTIAN, 1981).

As ações obtidas com o emprego do açúcar em feridas são: oferta de nutrição às células lesadas, diminuição do odor exalado, drenagem de exsudação, redução do edema inflamatório, diminuição do $\mathrm{pH}$, dilatação dos pequenos vasos sanguíneos, formação de uma camada protetora de proteína, liberação de calor ao dissolver-se, atração de macrófagos reduzindo a necessidade de debridamento cirúrgico e estimulação dos tecidos de granulação e epitelial (MATHEWS; BINNINGTON, 2002). O uso do açúcar é indicado na fase inflamatória da cicatrização até o início da fase de reparação. Afrequência de troca do curativo depende da rapidez com que o açúcar é diluído pelos exsudatos, podendo variar de uma a três vezes ao dia (HEDLUND, 2008).

Entretanto, em algumas situações, o açúcar granulado tem seu uso limitado pela impossibilidade de preenchimento total da área afetada, como em feridas com pequeno orifício de abertura, associada ao despregueamento do subcutâneo, formando feridas em "túneis" ou em locais de difícil aderência dos grânulos, como região perineal e proeminências ósseas. Nesse contexto, o açúcar em forma de gel representa uma alternativa plausível, reunindo os benefícios obtidos com o uso do açúcar granulado e oferecendo melhor aplicabilidade devido à característica de sua apresentação. Diante disso, os objetivos deste trabalho foram comparar o tratamento tópico de feridas em cães com açúcar granulado ou em gel até a formação de tecido de granulação e analisar amostras microbiológicas coletadas das feridas antes e durante os tratamentos.

\section{MATERIAL E MÉTODOS}

Foram tratadas 16 feridas cutâneas de cães, provenientes da casuística do setor de clínica-cirúrgica do Hospital Veterinário Universitário da UFSM, durante o mês de setembro de 2010 a outubro de 2011. Incluíramse ao experimento cães de ambos os sexos, com idade média de 64,0 meses ( $\pm 34,9$ meses) e peso corporal médio de $21,2 \mathrm{~kg}$ ( $\pm 15,2$ kilogramas). Foram formados dois grupos ao acaso com oito feridas em cada, sendo identificados como grupo A (açúcar) em que as feridas foram tratadas com açúcar granulado e grupo $\mathrm{G}$ (gel) em que foram tratadas com gel de açúcar.

As feridas foram classificadas de acordo com WALDRON \& ZIMMERMAN-POPE (2007), nas quais foi considerada a densidade microbiana, progressão da infecção e apresentação clínico-cirúrgica. Swabs das lesões para cultura bacteriana foram coletados a fim de determinar os micro-organismos envolvidos nas infecções das feridas desses pacientes.

Também foram mensuradas as áreas das feridas. Para tal, o contorno delas foi desenhado em um papel vegetal diretamente no animal (Figura 1A) e posteriormente transcrito para uma folha de papel convencional (Figura 1B). Essa folha era digitalizada com escâner, gerando uma imagem em formato BMP. Posteriormente, realizava-se a etapa de préprocessamento da imagem digitalizada com o programa PAINT, para garantir maior homogeneidade de cor no interior da imagem e definição de contornos precisos (Figura 1C). Adotou-se a cor vermelha para representar a área da ferida. Para finalizar, a imagem era submetida à execução do programa Conta Pixel* para fazer a contagem do número de pixels de interesse e cálculo de área da ferida (Figura 1D).

Registros fotográficos também foram realizados a fim de observar a evolução da cicatrização. Amostras de sangue para leucograma e temperatura retal foram mensuradas, pois se esses animais apresentassem leucocitose com desvio à esquerda e hipertermia eram candidatos ao uso de antibiótico e por esse motivo não eram inclusos no experimento.

O tratamento das feridas era iniciado imediatamente após a classificação e avaliação dos parâmetros. Era realizada tricotomia ampla da área e limpeza da ferida com solução salina estéril por meio de jatos sob pressão com seringa de $60 \mathrm{ml}$ e agulha calibre 40x8 até a completa remoção das sujidades existentes. Uma vez higienizadas, as feridas eram secas com gaze estéril e cobertas até recobrir as bordas com açúcar granulado (Figura 1E) ou gel de açúcar (Figura 1F), dependendo do grupo, e aplicavam-se camadas de gaze estéril e atadura para manter o produto fixado ao leito da ferida. Os curativos eram realizados duas vezes ao dia até a formação de tecido de granulação, até que o leito da ferida estivesse próximo das bordas e não houvesse mais drenagem de exsudatos. 


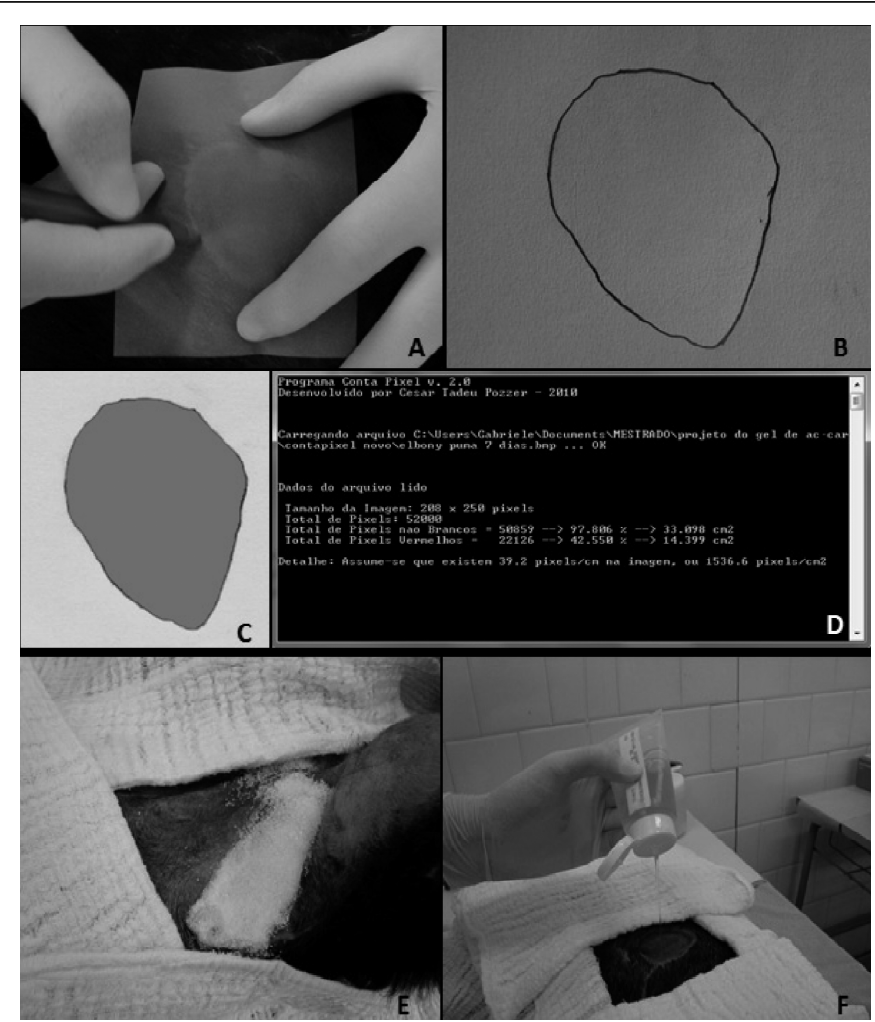

Figura $1 \mathrm{~A}$ - Contorno da ferida sendo desenhado em papel vegetal. B Desenho do contorno da ferida transcrito em papel convencional. C - Imagem digitalizada da ferida em etapa de pré-processamento com o programa PAINT. D - Imagem submetida à execução do programa Conta Pixel gerando contagem do número de pixels de interesse e área da ferida. E - Colocação de açúcar granulado no leito da ferida. F Colocação de gel de açúcar no leito da ferida.

Posteriormente, os animais recebiam alta com prescrição de duas limpezas diárias da ferida com solução salina estéril e aplicação de pomada a base de óxido de zinco até completa epitelização.

Semanalmente, eram repetidas as coletas de amostras para cultura bacteriológica, desenho da ferida, registro fotográfico e observação do aspecto da ferida, o qual definia o término do tratamento com o açúcar granulado ou o gel de açúcar. Os medicamentos usados para controle de dor variaram entre meloxicam $(0,2 \mathrm{mg}$ $\mathrm{kg}^{-1}$ no $1^{\mathrm{o}}$ dia, seguido de $0,1 \mathrm{mg} \mathrm{kg}^{-1}$, SID, por até 5 dias), dipirona sódica (25 $\mathrm{mg} \mathrm{kg}^{-1}$, BID , 3 dias) e tramadol (4mg kg-1 , BID, 3 dias), sendo o protocolo de analgesia prescrito conforme a necessidade de cada paciente.

O gel de açúcar utilizado nesse experimento foi preparado a partir de uma solução concentrada de açúcar granulado e sua manipulação foi realizada na Farmácia Escola da UFSM. Para sua formulação, aqueceram-se $50 \mathrm{ml}$ de água destilada até $80^{\circ} \mathrm{C}$.
Dissolveram-se $92 \mathrm{~g}$ de açúcar e esperou-se a temperatura atingir $90^{\circ} \mathrm{C}$. Ao chegar aos $90^{\circ} \mathrm{C}$, aguardaram-se mais cinco minutos homogeneizando o produto algumas vezes. Retirou-se do aquecimento e esperou-se a temperatura diminuir entre 70 e $60^{\circ} \mathrm{C}$ e então se acrescentaram dois gramas de hidroxietilcelulose e agitou-se até o seu resfriamento.

Para a comparação da área das feridas dentro dos grupos, foi utilizado o teste-t para amostras pareadas, quando as amostras apresentavam distribuição normal, ou o teste de Wilcoxon para análise em ranks, quando essa condição não era atendida, ambos com nível de significância $\alpha=0,05$. Para a comparação entre os grupos, foi utilizado o teste-t para amostras com distribuição normal ou o teste de MannWhitney para amostras sem distribuição normal $(\mathrm{P}<0,05)$. Para análise da frequência de exame bacteriológico negativo, foram utilizados testes de associação baseados na estatística Qui-quadrado: 
Teste de McNemar para os diferentes momentos em cada grupo e o Teste Exato de Fischer para a comparação da frequência entre os grupos.

\section{RESULTADOS E DISCUSSÃO}

O gel de açúcar mostrou ser de melhor aplicabilidade que o açúcar granulado, pois sua consistência de gel permitiu melhor adesão do produto nas feridas e preenchimento de espaços no subcutâneo de forma mais efetiva que o açúcar granulado. A consistência de gel foi oferecida pela hidroxietilcelulose, que é um polímero de caráter não-iônico derivado da celulose e usado como agente regulador da viscosidade e espessante de produtos tópicos (CAPUCHO, 2007). Neste experimento, sua ação foi fundamental por manter o gel de açúcar na consistência desejada, permitindo armazenamento em temperatura ambiente e favorecendo a praticidade do seu uso.

Seguindo a classificação das feridas de WALDRON \& ZIMMERMAN-POPE (2007), observouse que, em relação à apresentação clínico-cirúrgica, todas as feridas foram classificadas como laceradas. Quanto à classe, 87,5\% foram classificadas como classe 3 e $12,5 \%$ como classe 2. Quanto à densidade microbiana, $75 \%$ foram classificadas como contaminadas e $25 \%$ como sujas.

Dentre as 16 feridas tratadas, predominaram as feridas por mordedura, com $31,25 \%$ dos casos, seguida de causas desconhecidas (18,75\%), ferimentos em que o animal enroscou-se em cerca de arame farpado $(12,25 \%)$, lesões causadas pelo uso de canaleta de alumínio para tratamento de fratura $(12,25 \%)$, deiscência de sutura $(12,25 \%)$, abscesso drenado $(6,25 \%)$ e atropelamento $(6,25 \%)$. Feridas por mordedura também foram a causa principal das feridas estudadas por MONTEIRO et al. (2007) em $25 \%$ dos seus casos, e em $50 \%$ para ARIAS et al. (2008).

As feridas por mordedura variaram entre classe 2 ou 3 , contaminadas ou sujas. Mesmo a literatura indicando o uso de antibiótico de amplo espectro por via intravenosa pelo menos durante a primeira consulta em animais gravemente feridos por mordedura (WALDRON \& ZIMMERMAN-POPE, 2007), nos animais deste estudo, independente da causa, não se optou pelo uso de qualquer forma de antibiótico, pois eles não se apresentaram severamente imunocomprometidos, nem com sinais sistêmicos de infecção (DERNELL, 2006).

No primeiro dia de tratamento, observou-se que todas as feridas apresentaram edema de bordas, $25 \%$ secreção purulenta, $43,75 \%$ necrose tecidual e $6,25 \%$ presença de miíase. Como as feridas eram avaliadas semanalmente, o tempo de tratamento utilizando gel ou açúcar granulado durou sete ou 14 dias. No grupo do açúcar granulado, apenas um animal foi liberado do uso desse produto aos sete dias, enquanto sete animais foram liberados aos 14. Já no grupo do gel de açúcar, três animais foram liberados do tratamento aos sete dias e cinco aos 14 , observandose uma pequena superioridade do gel com relação ao tempo de tratamento. HADDAD et al. (2000) levaram em média 53 dias utilizando açúcar em feridas de pacientes humanos. Entretanto, eles utilizaram o açúcar até completa epitelização, ao contrário deste experimento, em que o açúcar foi utilizado até formação de tecido de granulação, até o leito da lesão ficar mais próximo das bordas e de não haver mais secreção.

Através das mensurações das áreas das feridas (Figura 2) realizadas pelo programa Conta Pixels e análise dos resultados, no grupo tratado com açúcar, pôde-se perceber diminuição estatisticamente significativa entre os dias 1 e $14(\mathrm{P}=0,036)$ e entre os dias 7 e $14(\mathrm{P}=0,008)$. No grupo tratado com gel, houve diminuição significativa da área das feridas em todos os momentos (entre os dias 1 e 7: $\mathrm{P}=0,039 ; 1$ e 14 : $\mathrm{P}=0,008 ; 7$ e 14: $\mathrm{P}=0,006$ ). Esses resultados demonstram que ambos os tratamentos foram efetivos para a cicatrização de feridas. Entretanto, o gel demonstrou precocidade na redução da área, quando comparado ao açúcar nos primeiros sete dias. Na comparação da diminuição da área entre os grupos, não se observou diferença estatística em nenhum momento.

Quanto ao local, as feridas predominantes foram as localizadas nos membros com $37,5 \%$ dos casos, seguido de região torácica $(25 \%)$, pescoço $(12,5 \%)$, abdômen $(12,5 \%)$, face $(6,25 \%)$ e pálpebra inferior $(6,25 \%)$. Nas feridas que envolveram membros, percebeuse, em algumas delas, retração cicatricial mais lenta, quando comparada às feridas das outras regiões, inclusive com aumento da área em três feridas entre o primeiro e sétimo dia de tratamento. Provavelmente, essa retração cicatricial mais lenta se deva à própria localização das lesões, pois LEPAULT et al. (2005) explicam que feridas em membros apresentam a fase inflamatória mais intensa e demorada, atrasando a reepitelização.

Além disso, MELO et al. (2009) salientam que a proporção da ferida que cicatriza por contração varia, dependendo das propriedades da pele vizinha, ou seja, a contração é mais pronunciada nas regiões de corpo que apresentam a pele frouxa do que nas regiões em que a pele está sob constante tensão, como ocorre na região distal dos membros. Essa afirmação foi perfeitamente confirmada nos animais deste experimento, no qual se percebeu uma retração cicatricial mais pronunciada nas feridas que envolveram face ou abdômen, quando comparadas às feridas dos membros. 

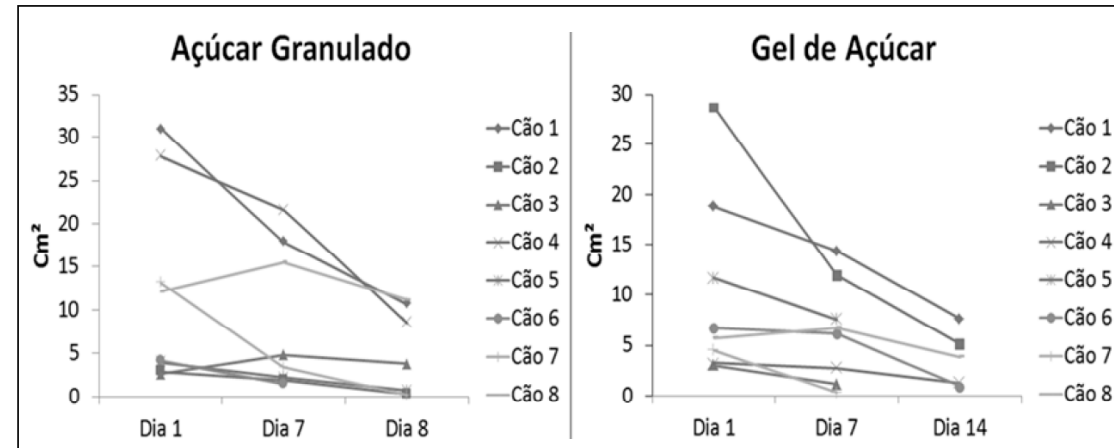

Figura 2 - Comparação da diminuição da área de cada ferida no grupo do açúcar granulado e gel de açúcar.

Quanto à cultura bacteriológica, Staphylococcus aureus foi a bactéria predominante, com $30,76 \%$ de isolamento, seguido de Staphylococcus epidermidis (26,92\%), Escherichia coli (11,53\%), Enterobacter aerogenes $(11,53 \%)$, Enterococcus faecalis $(11,53 \%)$, Streptococcus agalactiae $(3,84 \%) \mathrm{e}$ Staphylococcus saprophyticus $(3,84 \%)$. Em estudos realizados por HADDAD et al. (2000) e MONTEIRO et al. (2007), Staphylococcus aureus também foi o microorganismo mais frequentemente isolado, provavelmente, porque esse agente pertence à flora normal da pele e tem capacidade de tornar-se, transitoriamente, residente em outro local, como uma ferida cutânea, a qual apresenta continuidade com a pele (RAHAL et al., 1983).

Observou-se, neste experimento e também no realizado por HADDAD et al. (2000), que, em três feridas de cada grupo, as bactérias alteraram a cada análise bacteriológica e quatro feridas do grupo do açúcar granulado e uma do grupo do gel de açúcar ainda apresentaram isolamento bacteriano no último dia de tratamento. Isso é passível de ocorrer, visto que os micro-organismos podem infectar o ferimento através de várias formas, como contato direto, ar, instrumental, superfície externa do paciente e, principalmente, através dos pelos e perdas dos curativos (CAMPOS et al., 2000). Entretanto, com quantidade insuficiente para determinar infecção, já que todas as feridas estavam sendo tratadas e apresentando sinais que DART et al. (2005) consideram como sendo de evolução cicatricial, com debridamento completo da ferida, presença de um leito de granulação saudável e início de epitelização.

Quanto à frequência de cultura bacteriológica negativa, o grupo do açúcar apresentou 25\% de exames negativos no primeiro dia, $25 \%$ no sétimo dia e $42,85 \%$ aos 14 dias. No grupo do gel, $25 \%$ das culturas deram negativas no primeiro dia, $62,50 \%$ no sétimo dia e $80 \%$ aos 14 dias. Apesar dos resultados obtidos, não houve diferença estatisticamente significativa entre os diferentes momentos de cada grupo, nem entre os grupos de açúcar e gel de açúcar, fato que pode ser atribuído ao pequeno número de amostras.

Neste experimento, optou-se por deixar o açúcar no leito da ferida entre uma troca e outra de curativo, pois, segundo RAHAL et al. (1983), o açúcaré bacteriostático e bactericida, devido à alta osmolaridade do xarope que se forma após algumas horas da sua aplicação sobre a ferida. Essa ação foi comprovada à medida que muitos exames bacteriológicos tornavamse negativos ao longo do tratamento.

Em relação à frequência de curativos, HADDAD et al. (1983) recomendam a troca do curativo com açúcar de $6 / 6$ ou de $8 / 8$ horas até que as feridas não sejam mais secretantes, aumentando-se os intervalos de troca para de 12/12 ou de 24/24 horas. Nos animais deste estudo, as trocas foram realizadas de 12/12 horas desde o primeiro dia com o objetivo de padronizar a frequência para posterior comparação entre os grupos já que as feridas não apresentavam graus muito variáveis de contaminação.

\section{CONCLUSÃO}

Com base nos resultados obtidos e analisados neste experimento, conclui-se que tanto o açúcar quanto o gel de açúcar são efetivos na cicatrização de feridas cutâneas em cães. Entretanto, o gel de açúcar apresenta precocidade na retração cicatricial nos primeiros sete dias de tratamento, quando comparado ao açúcar, e uma tendência maior que o açúcar granulado em tornar negativos os exames bacteriológicos das feridas cutâneas. Além disso, deixar o açúcar entre uma troca e outra não acarreta em meio de cultura para as bactérias. 


\section{AGRADECIMENTOS}

Ao professor Cézar Pozzer, pela produção do programa Conta Pixels. À professora Gizele Scotti do Canto e à Farmácia Escola da UFSM, pela manipulação do gel de açúcar.

\section{INFORME VERBAL}

* Programa Conta Pixel - desenvolvido pelo Professor Cesar Tadeu Pozzer, do Departamento de Eletrônica e Computação, Laboratório LaCA (Laboratório de Computação Aplicada) da UFSM, especialmente para este experimento.

\section{COMITÊ DE ÉTICA}

Número do parecer: 081/2011.

\section{REFERÊNCIAS}

ALVES, D.F.S. et al. Efeitos da aplicação tópica do mel de melipona subnitida em feridas infectadas de ratos. Revista do Colégio Brasileiro de Cirurgiões, v.35, n.3, p.188-193, 2008. Disponível em: <http://www.scielo.br/scielo.php?pid=S0100$69912008000300010 \&$ script=sci_abstract\&tlng=pt $>$. Acesso em: 16 jun. 2012. doi: 10.1590/S0100-69912008000300010.

ARIAS, M.V.B. et al. Identificação da suscetibilidade antimicrobiana de bactérias isoladas de cães e gatos com feridas traumáticas contaminadas e infectadas. Ciências Agrárias. v.29, n.4, p.861-874, 2008.

CAMPOS, M.C.P.S et al. Tratamento de feridas infectadas utilizando Calendula officinalis. Homeopatia Brasileira, v.6, n.1, p.22-28, 2000 .

CAPUCHO, H.C. Desenvolvimento de formulações tópicas contendo papaína para o tratamento de feridas. 2007. 102f. Dissertação de Mestrado em Ciências Farmacêuticas Curso de Pós- Graduação em Ciências Farmacêuticas de Ribeirão Preto, Universidade de São Paulo, SP.

CHIRIFE, J. et al. In vitro study of bacterial growth inhibition in concentrated sugar solutions: microbiological basis for the use of sugar in treating infected wounds. Antimicrobial Agents and Chemotherapy, v.23, n.5, p.766-773, 1983. Disponível em: 〈http://aac.asm.org/content/23/5/766.full.pdf+html〉. Acesso em: 18 jun. 2012. doi: 10.1128/AAC.23.5.766.

CHRISTIAN, J.H.B. Specific solute effects on microbial water relations. In: ROCKLAND, L.B.; STEWART, G.F. Water activity: influences on food quality. New York: Academic, 1981. p.825-854.

DART, A.J. et al. Topical treatments in equine wound management. Veterinary Clinics Equine Practice, v.21, n.1, p.77-89, 2005.
Disponível em: <http://www.vetequine.theclinics.com/article/ S0749-0739(04)00084-7/fulltext>. Acesso em: 18 jun. 2012. doi: 10.1016/j.cveq.2004.11.003.

DERNELL, W.S. Initial wound management. Veterinary Clinics of North America. Small Animal Practice, v.36, n.4, p.713738, 2006. Disponível em: <http://www.vetsmall.theclinics.com/ article/S0195-5616(06)00045-3/fulltext>. Acesso em: 18 jun. 2012. doi: 10.1016/j.cvsm.2006.04.003.

HADDAD. M.C.L. et al. O uso do açúcar nas feridas infectadas. Revista Brasileira de Enfermagem, v.36, n.2, p.152-154, 1983.

HADDAD, M.C.L. et al. Influência do açúcar no processo de cicatrização de incisões cirúrgicas infectadas. Revista LatinoAmericana de Enfermagem, v.8, n.1, p.57-65, 2000. Disponível em: <http://www.scielo.br/scielo.php?script=sci_arttext\&pid=S0104$11692000000100009 \& \operatorname{lng}=$ pt\&nrm=iso>. Acesso em: 17 jun. 2012. doi: 10.1590/S0104-11692000000100009.

HEDLUND, C.S. Cirurgia do sistema tegumentar. In: FOSSUM, T.W. Cirurgia de pequenos animais. 3.ed. Rio de Janeiro: Elsevier, 2008. Cap.15, p.159-259.

LEPAULT, E. et al. Comparative study on microvascular occlusion and apoptosis in body and limb wounds in the horse. Wound Repair and Regeneration, v.13, n.5, p.520-529, 2005. Disponível em: <http://onlinelibrary.wiley.com/doi/ 10.1111/j.1067-1927.2005.00073.x/full>. Acesso em: 17 jun. 2012. doi: 10.1111/j.1067-1927.2005.00073.x.

MATHEWS, K.A.; BINNINGTON, A.G. Wound management with sugar. Compendium on Continuing Education for the Practicing Veterinarian, v.24, n.1, p.41-50, 2002.

MELO, U.P. et al. Fisiopatologia da cicatrização das feridas nos equinos. Revista do Conselho Federal de Medicina Veterinária, v.15, n.48 p.32-42, 2009.

MONTEIRO, V.L.C. et al. Cana-de-açúcar no tratamento de feridas cutâneas por segunda ou terceira intenção. Medicina Veterinária, v.1, n.1, p.1-8, 2007.

PIEPER, B.; CALIRI, M.H. Nontraditional wound care: a review of the evidence for the use of sugar, papaya/papain, and fatty acids. Journal of Wound, Ostomy and Continence Nursing, v.30, n.4, p.175-183, 2003.

RAHAL, F. et al. O açúcar no tratamento local das infecções de feridas cirúrgicas. Revista do Colégio Brasileiro de Cirurgiões, v.10, p.135-136, 1983.

WALDRON, D.R; ZIMMERMAN-POPE, N. Ferimentos cutâneos superficiais. In: SLATTER, D. Manual de cirurgia de pequenos animais. 3ed. São Paulo: Manole, 2007. V.1, cap. 21 , p.259-273. 